\title{
The Method of Testing for Asbestos in Electronic and Electric Products through Polarizing Microscope and X-Ray Diffraction
}

\author{
Hongwei Wang1, Jun Liu², Qiang Ma1, Hongwei Su${ }^{3}$, Deyong Liư ${ }^{3}$, Junfang Li¹, Hua Bai1 \\ ${ }^{1}$ Institute of Industrial and Consumer Product Safety, Chinese Academy of Inspection and Quarantine, Beijing, China \\ ${ }^{2}$ Beijing Petrochemical Engineering Co., Ltd., Beijing, China \\ ${ }^{3}$ China Testing and Testing Group Co., Ltd., Shenzhen, China \\ Email: wanghongwei-1978@163.com
}

How to cite this paper: Wang, H.W., Liu, J., Ma, Q., Su, H.W., Liu, D.Y., Li, J.F. and Bai, H. (2019) The Method of Testing for Asbestos in Electronic and Electric Products through Polarizing Microscope and X-Ray Diffraction. Journal of Power and Energy Engineering, 7, 35-41.

https://doi.org/10.4236/jpee.2019.711004

Received: May 28, 2019

Accepted: November 24, 2019

Published: November 27, 2019

\begin{abstract}
Asbestos is widely applied in such sectors as manufacturing automobiles, tractors, chemical industrial equipment, and electric equipment. Asbestos fiber is harmful to human health. Therefore, the technology of testing for asbestos in products is especially important. At present, in our country's national specifications, there is no determination method or specification that is applicable to the asbestos in electronic and electric products. In this article, the components of asbestos in electronic and electric products are identified using the method of combining polarizing microscope with X-ray diffractometer. This method is simple, fast, highly reliable, and suitable to be widely adopted.
\end{abstract}

\section{Keywords}

Asbestos, Polarizing Microscope, X-Ray Diffraction

\section{Introduction}

Asbestos is a generic term for natural fibrous silicon-based minerals, which are generally divided into the two major categories of chrysotile and amphibole asbestos, and are extensively applied, more importantly in such sectors as manufacturing automobiles, tractors, chemical industrial equipment, and electric equipment [1]. As scientific research has indicated, asbestos fiber has a harmful effect on human health. International Agency for Research on Cancer (IARC) has announced that asbestos is a Class A carcinogen. Because of this, products containing asbestos are prohibited from being imported to such countries as the 
US (EPA), European Union (Appendix XVII in REACH), Japan, South Korea, Brazil, Thailand, and Australia. Moreover, many multinational companies such as SONY, DELL, Sharp, and IBM have also all clearly stated that the use of asbestos is not allowed in their products and raw materials [2] [3] [4] [5]. It is an issue of great concern to our country's supervision organizations, manufacturers, and academic circles to work out the method of testing for asbestos in electronic and electric products, and avoid the harm from asbestos and the risk in trade.

The results from checking new standards with the Library of Standards of China National Institute of Standardization indicate that, currently, there is no applicable specification available in our country for the method of determining the asbestos in electronic and electric products.

\section{Experiment}

\subsection{Abstract of Determination Method}

After pretreatment, specimens are made suitable for analytic use. Results of test are obtained after observation with polarizing microscopes, and qualitative test results are made available after confirmation with X-ray diffractometers [6] [7].

If no fibrous particle is found after three potions of specimens ( $\geq 300$ particles) are observed using stereomicroscopes, it will be determined that no asbestos is observed. If there is the existence of fibrous particles, a further test will be done using polarizing microscopes. If the fibrous particles are not asbestos fibers after the observation through polarizing microscopes, it will be determined that no asbestos is observed. If the fibrous particles observed through polarizing microscopes have all the optical characteristics of a certain type of asbestos, further confirmation will be made using X-ray diffractometers. If diffraction peaks characteristic of asbestos are found during the test based on X-ray diffraction, asbestos will have been observed. Otherwise, no asbestos has been observed (as shown in Figure 1).

\subsection{Pretreatment of Specimens}

Break up specimens to appropriate size in an appropriate way. Take out about 5 $\mathrm{g}$ of broken specimens and put them into a crucible, before placing it in a muffle furnace. Incinerate them for $1 \mathrm{~h}$ at $450^{\circ} \mathrm{C} \pm 10^{\circ} \mathrm{C}$, and remove organic substances. Take out the crucible and place it in a dryer to cool down until it reaches the room temperature. Then grind up the incinerated specimens in an agate mortar, and sift them through a metallic sieve in which the openings are $425 \mu \mathrm{m}$ - $500 \mu \mathrm{m}$ in diameter.

\subsection{Initial Screening under Stereomicroscopes}

Place under a stereomicroscope the specimens carried by a sheet of glass, and observe them to see if there is any fibrous particle. If any fibrous particle exists, 


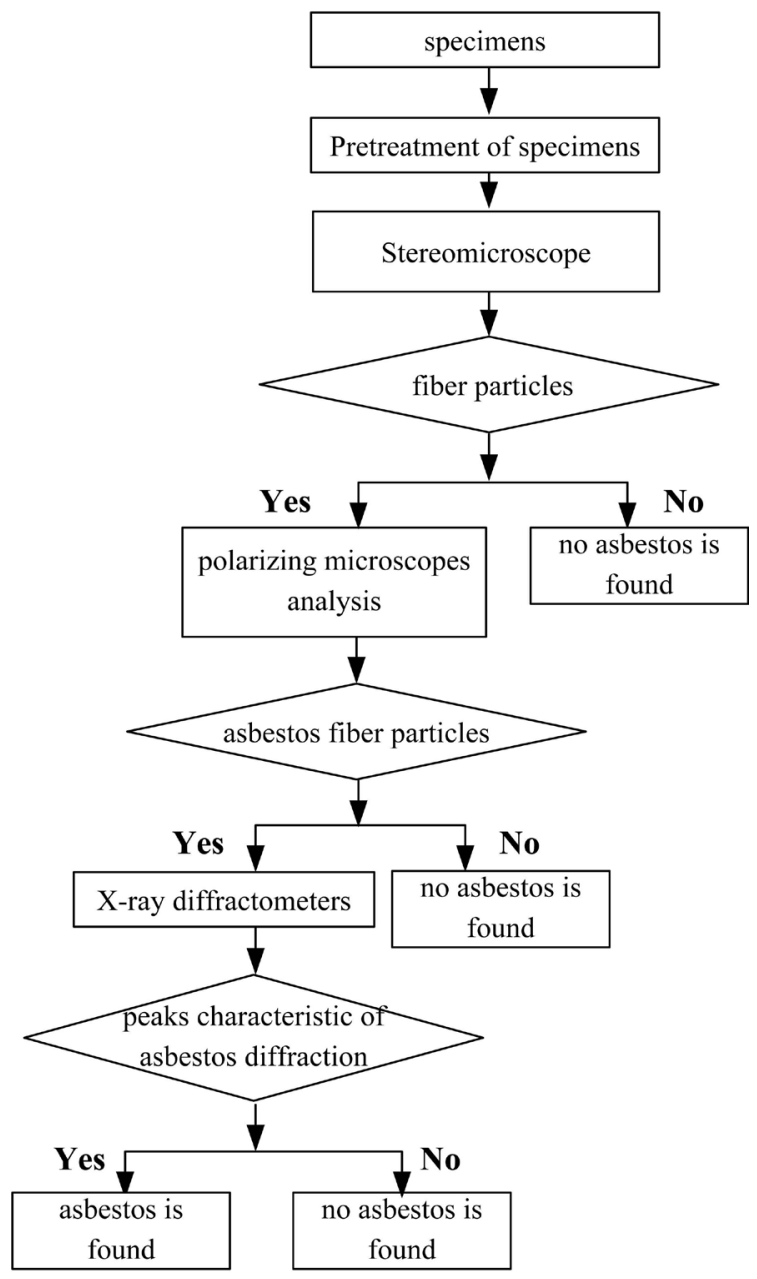

Figure 1 . The determination procedure with polarizing microscopes and X-ray diffraction.

observe the appearance and physical features of it, and record its fibrous characteristics.

Take at least three portions of the specimens ( $\geq 300$ particles) for observation. If no fibrous particle is found among three portions of the specimens, it will be determined that the specimens test negative for asbestos. If any fibrous particle exists, further test will be made with the help of a polarizing microscope.

\subsection{Test under Polarizing Microscopes}

Initially determine the possible fiber type, according to the fibrous characteristics observed under a stereomicroscope, and apply drops of the oil with an appropriate refractivity (oil of certain refractive index (immersion oil): 1) immersion oil's refractivity $n_{D}^{25}=1.550$ for chrysotile; 2 ) immersion oil's refractivity $n_{D}^{25}=1.700$ for crocidolite; 3 ) immersion oil's refractivity $n_{D}^{25}=1.670$ or 1.680 for amosite; 4) immersion oil's refractivity $n_{D}^{25}=1.605$ for anthophyllite and tremolite; 5) immersion oil's refractivity $n_{D}^{25}=1.640$ or 1.630 for actinolite ). Cover them with a sheet of glass, so as to immerse the specimens. Place them under a polarizing microscope to observe the optical characteristics of the fiber 
(elongation, birefringence, extinction, pleochroism, and discrete dyeing property). Take more portions of specimens if unable to determine the possible fiber types, and apply the oil of different refractive indexes for observation. See Table 1 for the optical characteristics showed by various types of asbestos in the oil of relevant refractive indexes under a polarizing microscope. If the fiber under observation has all the optical features of a certain type of asbestos, it will be initially determined that the fiber under observation is the asbestos fiber of this type, and further confirmation will be made using X-ray diffractometers. Otherwise, it will be determined that the fiber under observation is not asbestos fiber particles, and no asbestos has been found in the specimens.

At least three portions are observed for each specimen.

\subsection{Confirmation with X-Ray Diffraction}

Place the specimens on the holder, and press them so as to make them flat. Determine whether the diffraction peaks characteristic of asbestos exist, under the analytic conditions for X-ray diffraction. Repeat the same test for three times. If any diffraction peak characteristic of asbestos is found during any of the three tests, it will be determined that asbestos is observed. If no diffraction peak characteristic of asbestos is found, it will be determined that no asbestos is observed [7].

\section{Results and Discussion}

\section{Results from Testing for the Standard Substances in 6 Types of Asbestos}

Figure 2 is the image showing the characteristic features of the standard substances in 6 types of asbestos observed under a polarizing microscope.

Fill the holder of the X-ray diffractometer evenly with analytic specimens. Determine whether the diffraction peaks characteristic of asbestos exist in the specimens for qualitative analysis, under the analytic conditions for X-ray diffractometer (see Table 2), and repeat the test for three times.

Determine whether the diffraction peaks characteristic of asbestos exist in the specimens for qualitative analysis, and repeat the test for three times in a row. If any diffraction peak characteristic of asbestos is found during any of the three

Table 1. The optical features of different types of asbestos fiber under a polarizing microscope.

\begin{tabular}{|c|c|c|c|c|c|c|c|}
\hline & Chrysotile & Hopfnerite & Anthophyllite & Actinolite & Amosite & Crocidolite & Hopfnerite \\
\hline Elongation $^{\mathrm{a}}$ & Length slow & Length slow & Length slow & Length slow & Length slow & Length fast & Length slow \\
\hline Birefringence & Brightest at $45^{\circ}$ & Brightest at $45^{\circ}$ & Brightest at $45^{\circ}$ & Brightest at $45^{\circ}$ & Brightest at $45^{\circ}$ & Brightest at $45^{\circ}$ & Brightest at $45^{\circ}$ \\
\hline Extinction $^{\mathrm{b}}$ & $\begin{array}{l}\text { Extinction in } \\
\text { parallel or } \\
\text { perpendicular } \\
\text { direction }\end{array}$ & $\begin{array}{l}\text { Extinction at a } \\
\text { small angle }\end{array}$ & $\begin{array}{l}\text { Extinction in } \\
\text { parallel or } \\
\text { perpendicular } \\
\text { direction }\end{array}$ & $\begin{array}{l}\text { Extinction in } \\
\text { parallel or } \\
\text { perpendicular } \\
\text { direction }\end{array}$ & $\begin{array}{l}\text { Extinction in } \\
\text { parallel or } \\
\text { perpendicular } \\
\text { direction }\end{array}$ & $\begin{array}{l}\text { Extinction in } \\
\text { parallel or } \\
\text { perpendicular } \\
\text { direction }\end{array}$ & $\begin{array}{l}\text { Extinction at a } \\
\text { small angle }\end{array}$ \\
\hline Pleochroism $^{c}$ & No & No & No & Weak & No & Yes & No \\
\hline
\end{tabular}




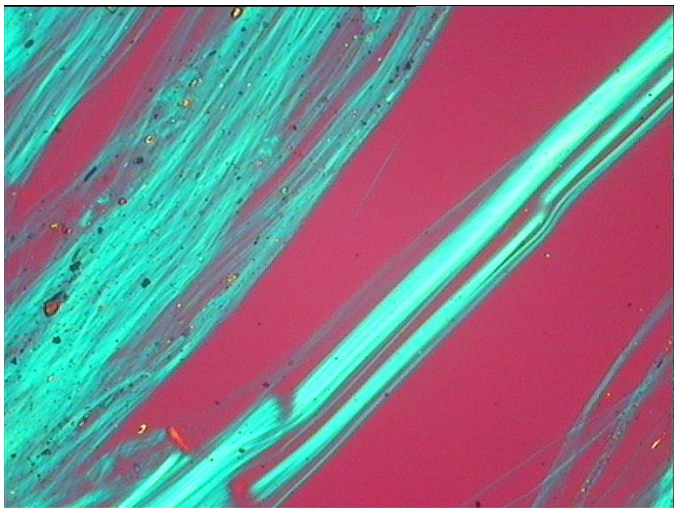

Actinolite- $\mathrm{Z}$ immersion oil's refractivity $\mathrm{n}=1.550$

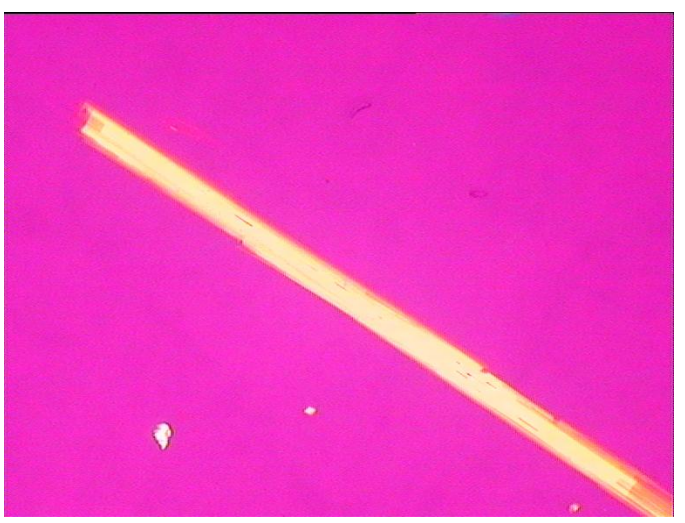

Hopfnerite immersion oil's refractivity $\mathrm{n}=1.625$

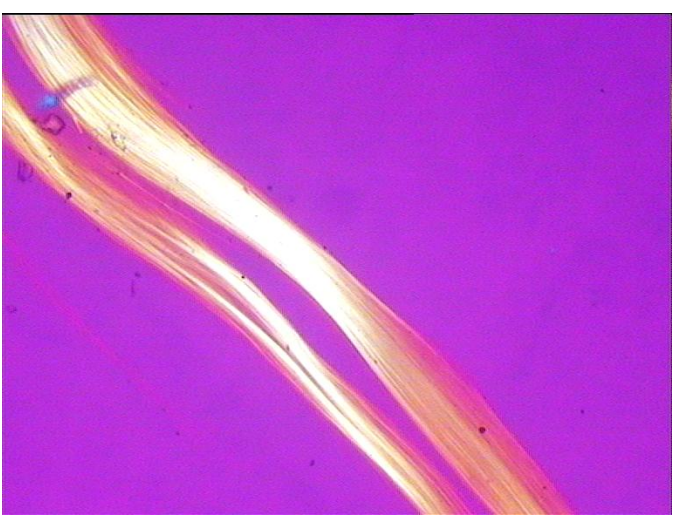

Actinolite immersion oil's refractivity $\mathrm{n}=1.640$

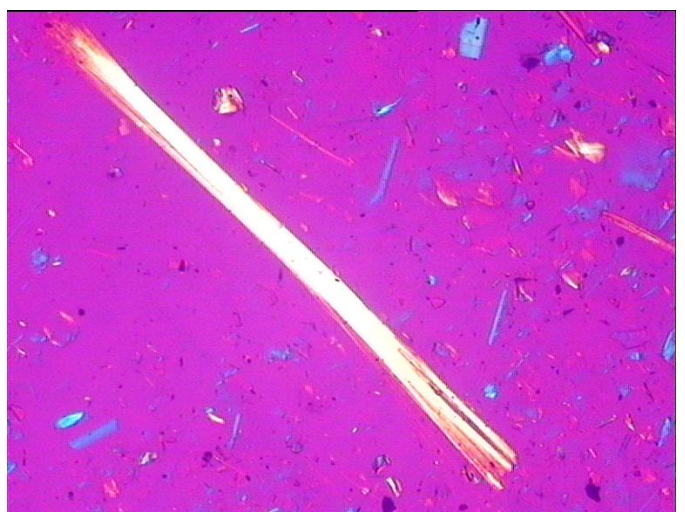

Antholite immersion oil's refractivity $\mathrm{n}=1.625$ 


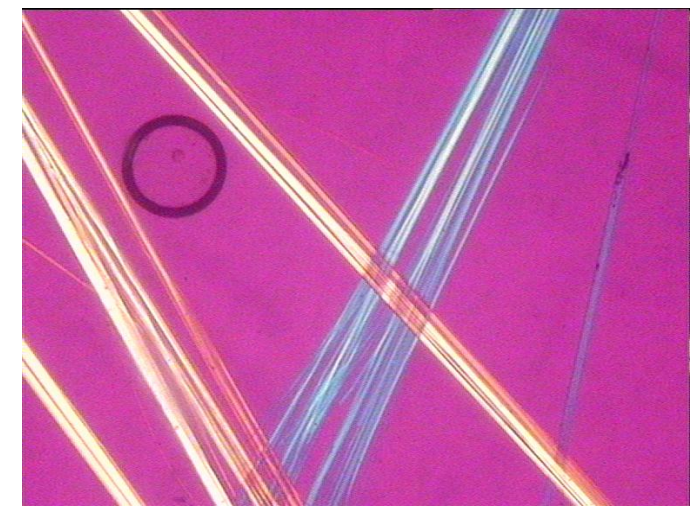

Amosite immersion oil's refractivity $\mathrm{n}=1.670$

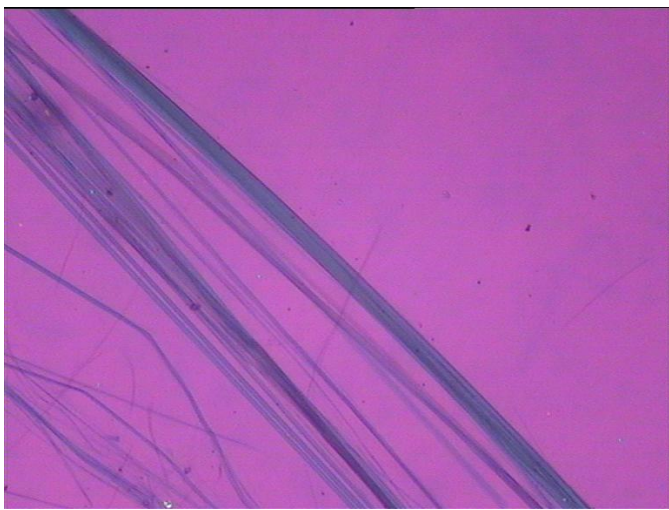

Crocidolite immersion oil's refractivity $\mathrm{n}=1.670$

Figure 2. Forms of various asbestos fibers.

Table 2. Conditions for qualitative analysis with X-ray diffraction device.

\begin{tabular}{cc}
\hline Predetermined items & Conditions for test \\
\hline X-ray anticathode & Copper $(\mathrm{Cu})$ \\
Tube voltage $(\mathrm{kV})$ & 40 to 45 \\
Tube current $(\mathrm{mA})$ & 30 to 45 \\
Monochromator (removing $\mathrm{K} \beta$ ray) & Ni filter \\
Scope of scanning $(2 \theta)\left({ }^{\circ}\right)$ & 5 to 64 \\
\hline
\end{tabular}

tests, it will be determined that asbestos exists. If no diffraction peak characteristic of asbestos is found, it will be determined that no asbestos exist.

\section{Conclusion}

The forms of 6 types of asbestos were worked out in this paper, including chrysotile, crocidolite, amosite, anthophylite, tremolite, and actinolite asbestos, the optical features and characteristic features of these types of asbestos fiber under a polarizing microscope were shown. Based on the combination of polarizing microscope and X-ray diffraction, the method of testing for asbestos in electronic and electric products has been obtained. In this method, polarizing microscope is used to initially screen specimens. The specimens having the particles 
similar to asbestos fibers are identified for the second time through the application of X-ray diffraction, largely enhancing the accuracy and reliability of the test.

\section{Acknowledgements}

The authors would like to acknowledge the financial support provided for this research work by Fund: National key R \& D program of China (2017YFF0210703).

\section{Conflicts of Interest}

The authors declare no conflicts of interest regarding the publication of this paper.

\section{References}

[1] NIOSH 7400 (1994) Asbestos and Other Fibers by Phase Contrast-Microscopy.

[2] ISO 14966 (2002) Ambient Air Determination of Numerical Concentration of Inorganic Fibrous Particles-Scanning Electron Microscopy Method.

[3] NIOSH-7402 (1994) Asbestos by TEM.

[4] SN/T 3798-2014 (2014) Determination of Asbestos in Building and Automobile Materials-Polarized Light Microscope.

[5] GB/T 23263-2009 (2009) Determination of Asbestos in Products.

[6] Zhang, M., Gao, X.L., et al. (2010) Quantitative Detection of Trace Asbestos by X-Ray Diffraction System. Rock and Mneral Analysis, 29, 319-322.

[7] Li, J.F., Yang, H.F., Yan, Y., et al. (2014) Study on Detection Technique of Asbestos in Consumer Products. Analytical Instruments, 1, 52-56. 